\title{
STATUS OF THE CRYOGENIC SYSTEM COMMISSIONING AT SNS *
}

\author{
F. Casagrande, I. Campisi, P. Gurd, D. Hatfield, M. Howell, D. Stout, H. Strong, SNS Project, \\ Oak Ridge National Laboratory, TN 37831

\section{Arenius, J. Creel, K. Dixon, V. Ganni, P. Knudsen, Thomas Jefferson National Accelerator Facility (TJNAF), Newport News, VA, 23606}

\begin{abstract}
The Spallation Neutron Source (SNS) is under construction at Oak Ridge National Laboratory. The cold section of the Linac consists of 81 superconducting radio frequency cavities cooled to $2.1 \mathrm{~K}$ by a 2400 Watt cryogenic refrigeration system. The major cryogenic system components include warm helium compressors with associated oil removal and gas management, $4.5 \mathrm{~K}$ cold box, $7000 \mathrm{~L}$ liquid helium dewar, $2.1 \mathrm{~K}$ cold box (consisting of 4 stages of cold compressors), gaseous helium storage, helium purification and gas impurity monitoring system, liquid nitrogen storage and the cryogenic distribution transfer line system. The overall system commissioning strategy and status will be presented.
\end{abstract}

\section{INTRODUCTION}

The SNS cryogenic system follows the TJNAF design with some modifications and with about half the refrigeration capacity. Figure 1 is a block diagram of the cryogenic system. Table 1 lists major cryogenic system load parameters. For a detailed description of the system design and loads see Ref. [1], [2], [3] and [4].

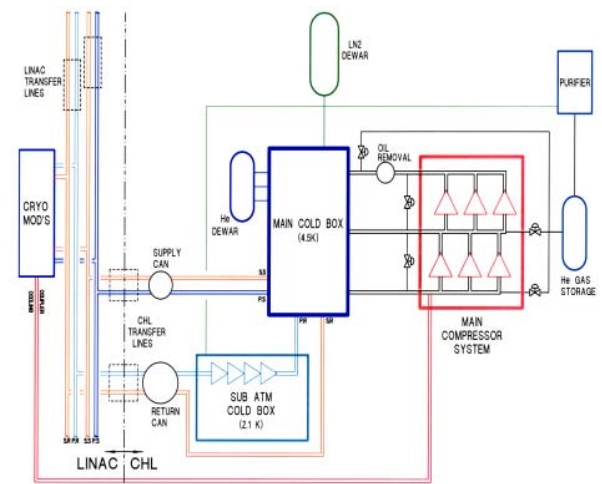

Figure 1: Cryogenic System Block diagram.

Table 1: Refrigeration Parameters for 32 Cryomodules

\begin{tabular}{|c|c|c|c|}
\hline & Primary & Secondary & Shield \\
\hline Temperature & $2.1 \mathrm{~K}$ & $4.5 \mathrm{~K}$ & $35-55 \mathrm{~K}$ \\
\hline Pressure & $0.041 \mathrm{bar}$ & $3 \mathrm{bar}$ & $4.0-3.0 \mathrm{bar}$ \\
\hline Static Load & $863 \mathrm{~W}$ & $5 \mathrm{~g} / \mathrm{s}$ & $6070 \mathrm{~W}$ \\
\hline Dynamic Load & $764 \mathrm{~W}$ & $2 \mathrm{~g} / \mathrm{s}$ & 0 \\
\hline Capacity & $2400 \mathrm{~W}$ & $15 \mathrm{~g} / \mathrm{s}$ & $8500 \mathrm{~W}$ \\
\hline
\end{tabular}

The SNS cryogenic system uses EPICS (Experimental Physics and Industrial Control System) to perform operator interface and high level control functions. The EPICS monitoring and control software runs in VME (Versa Module Europa) based IOCs (Input/Output Controllers) and in "soft IOCs" in a Linux box. The IOCs perform all automatic control sequences and almost all PID control loop execution which includes temperature, pressure, flow and valve position control. Operator interface workstations use the Linux operating system on standard personal computers. Figure 2 shows a typical operator workstation control screen. Allen-Bradley PLCs (Programmable Logic Controllers) are used to provide low level controls and also for equipment protection interlocks. In addition, the $4.5 \mathrm{~K}$ cold box PLC contains all the software for protecting and optimizing the performance of the turbines. Most of the sensors and actuators are connected to the PLCs. The system includes 16 PLCs, 11 IOCs, and 5 operator workstations. The design, programming, installation, checkout, and commissioning of the control system was performed by SNS personnel.

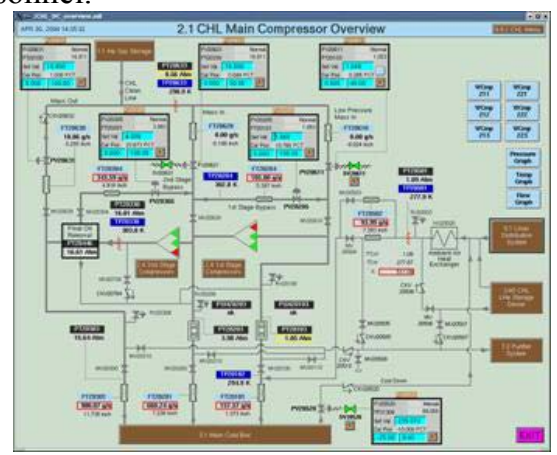

Figure 2: Control Screen.

\section{COMMISSIONING}

The major subsystems were designed to be tested independently in sequence starting with the warm helium compressors, followed by the $4.5 \mathrm{~K}$ cold box (without the $2.1 \mathrm{~K}$ cold box) with a $20 \mathrm{~kW}$ primary and $10 \mathrm{~kW}$ shield load heaters, and finally the $2.1 \mathrm{~K}$ cold box. Figure 3 shows the System Test Configuration.

*SNS is managed by UT-Battelle, LLC, under contract DE-AC0500OR22725 for the U.S. Department of Energy. SNS is a partnership of six national laboratories: Argonne, Brookhaven, Jefferson, Lawrence Berkeley, Los Alamos and Oak Ridge 


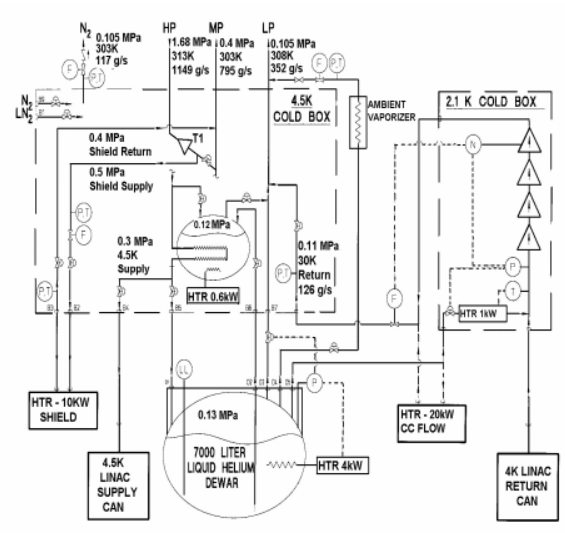

Figure 3: System Test Configuration.

In December 2003 the commissioning of the Warm Compressors started. A number of initial problems were discovered, including reversed oil heat exchanger seals, oil relief valves and oil circuit bypass valves. The vendor quickly addressed these problems and corrected the deficiencies. During the performance testing, the compressors met the performance requirements although one of the second stage machines appears to be noisier than the rest. Recently we discovered that oil injection orifices were missing.

In May 2004 all the cold compressors' instrumentation electrical connectors (4 per compressor) were confirmed to be leaking. An analysis by the cold compressor manufacturer with the connector sub-supplier indicated the sub-supplier had lost the technology to produce the connectors which could withstand cryogenic conditions. This cryogenic connector model had previously been used very successfully. After many months of iteration with the manufacturer of the electrical connectors in trying to recapture the technology we decided to move ahead with a feed-through design developed at SNS. We are currently waiting for the replacements from the cold compressor manufacturer once the connectors have been re-qualified.

In July 2004 the 4.5K Cold Box liquefaction and refrigeration modes at the nominal design ("T-S") conditions were tested. The plant met the liquefaction capacity requirement. However, to achieve the $4.5 \mathrm{~K}$ refrigeration capacity it was necessary to reduce the intended $4 \mathrm{~atm}$ inter-stage system operating pressure to $2.8 \mathrm{~atm}$. For all tests the $\mathrm{LN}_{2}$ consumption was higher than the design, approximately $20 \%$ for the liquefaction mode and $50 \%$ for the refrigeration mode. From preliminary analysis it appears that the top heat exchanger is not performing to specification. We are working with the cold box manufacturer to evaluate the measures necessary to correct the current operating parameters and nitrogen consumption to the intended design goals.

In August 2004 the Cryogenic Distribution System [5] was successfully commissioned with one Medium Beta Cryomodule and only simple cryogenic jumpers to connect the supply branch to the return branch of the transfer lines.
In December 2004 we started testing the $2.1 \mathrm{~K}$ Cold Box system with only 5 Cryomodules in the Linac tunnel and the same set of jumpers used to commission the cryogenic distribution system at $4.5 \mathrm{~K}$. After only a few days of tuning and system checks/verifications $2.1 \mathrm{~K}$ was achieved in the SNS Superconducting Linac.

Since January 2005 we have been cooling down one cryomodule per week and focused primarily on RF testing integration at $4.5 \mathrm{~K}[6]$.

In March and April 2005 we conducted a total of two more weeks of $2 \mathrm{~K}$ testing to study the system stability and performance. Figures 4-7 show some data analysis on the cold compressors performance somewhat similar to the TJNAF system [7].

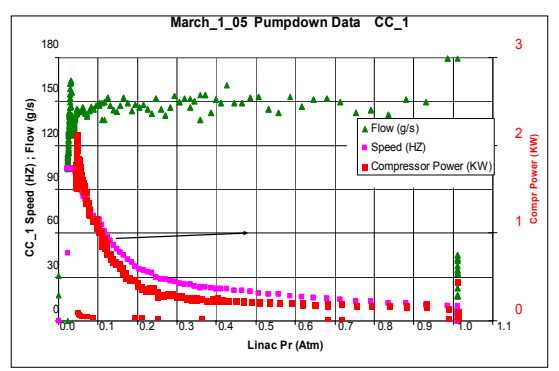

Figure 4: Cold Compressor 1 Pump down.

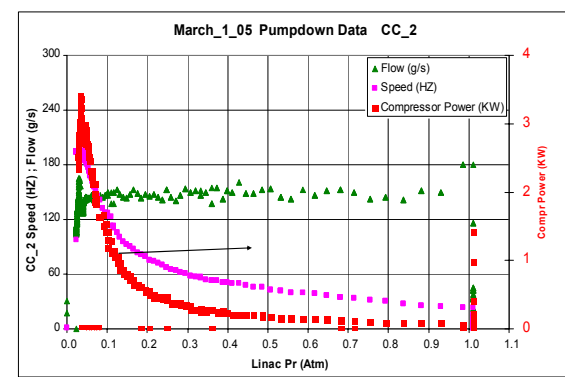

Figure 5: Cold Compressor 2 Pump down.

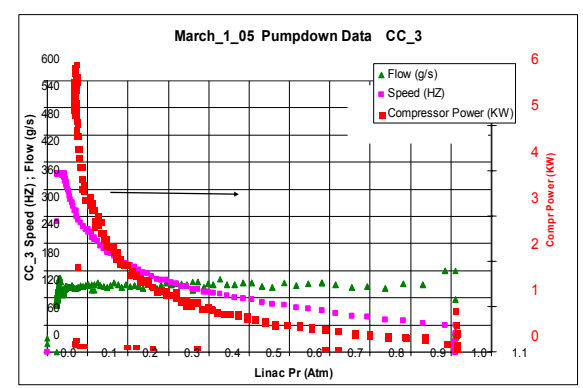

Figure 6: Cold Compressor 3 Pump down.

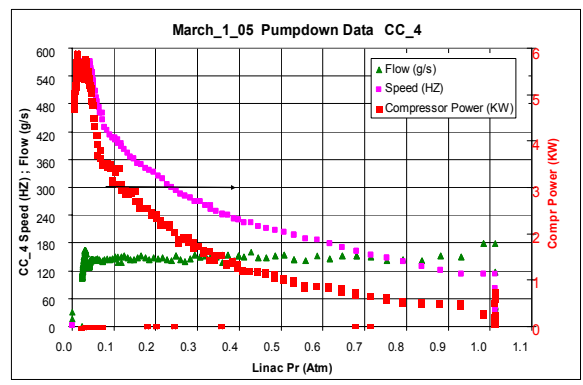

Figure 7: Cold Compressor 4 Pump down. 
The preliminary analysis confirms that the design load specification capacity of $2.4 \mathrm{KW} \quad(120 \mathrm{~g} / \mathrm{s}$ of cold compressor flow) at $2.1 \mathrm{~K}$ is achieved even though some issues concerning the unexpectedly low Power Factor of the cold compressor motors are still under investigation.

Out of the 23 total Cryomodules, 20 have been tested at $4.5 \mathrm{~K}$. Three of these cryomodules were repaired for insulating vacuum leaks (cold feedthroughs) at SNS. Two of the repaired cryomodules have been cooled and tested successfully; the third repair has just been completed and will be cooled down next. Of the last two cryomodules one has a $\mathrm{Ti} / \mathrm{Ti}-\mathrm{Nb}$ vessel leak and the other a primary circuit leak.

The insulating vacuum integrity in the cryomodules is one of our main issues right now in the Superconducting Linac (SCL); Figure 8[8] shows some insulating vacuum rate of rise measurements.

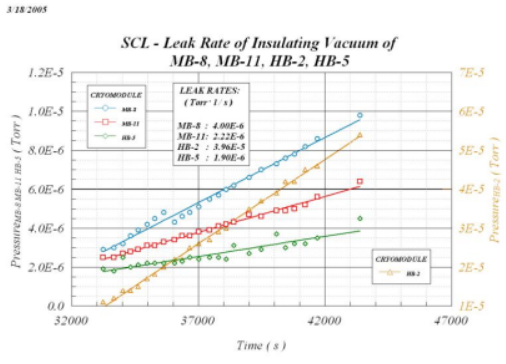

Figure 8: Leak Rate of Insulating Vacuums.

Approximately $50 \%$ of the cryomodules have a leak from the process lines to the insulating vacuum space and require constant pumping. Only one cryomodule so far has a leak from the insulating vacuum into the beam line, see Figure 9.

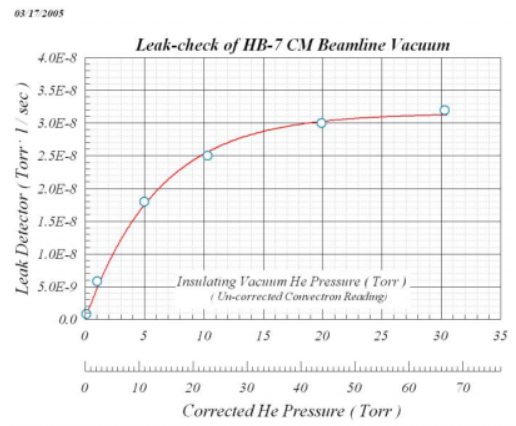

Figure 9: HB-7 Beamline leak rate.

In the future we will have to develop a plan to repair the leaks and/or design a permanent vacuum system in the Linac tunnel to support beam operations.

\section{REMARKS}

The cryogenic system has been operating continuously since November 2004 and unmanned for at least one 8 hour shift per day since the end of December 2004. The system has proven to be very flexible and capacity can be turned down very easily. We have been using different combinations of turbines and system pressures depending on the load requirements and/or modes of operation. One of the most important technical components has been the $7000 \mathrm{~L}$ dewar design/interface and incorporation in the system not only for commissioning and testing purposes but to support normal operations.

\section{CONCLUSIONS}

The SNS cryogenic system has been successfully commissioned and has been operating to support RF testing for more than 5 months now. The success of the project is the result of the careful design, excellent planning [9], execution and hard work of many people and the outstanding professionalism and technical expertise of the companies that supplied the subsystem components (PHPK, Linde/BOC, Air Liquide, S2M, Chart Industries, etc.)

\section{ACKNOWLEDGEMENTS}

Special thanks go to Dr.V.Ganni and the entire TJNAF cryogenic group for the design, technical support, profound cryogenic knowledge and help in the start up and operational setup of the system.

\section{REFERENCES}

[1] D.Arenius et all. "Cryogenic System for the Spallation Neutron Source" CEC vol.49, 2004

[2] U.Fleck et all. "4.5K Cold Box for SNS-A successful Cooperation" CEC vol 49, 2004

[3] M.White "Spallation Neutron Source" CEC vol 47, 2002

[4] E.F.Daly et all. "Spallation Neutron Source Cryomodule Heat Loads and Thermal Design" CEC vol.47 2002

[5] M.P.Howell et all. "Spallation Neutron Source Cryogenic Transfer Lines" CEC vol 49. 2004

[6] I.Campisi these proceedings

[7] V.Ganni et all. "Design, Fabrication, Commissioning and Testing of a $250 \mathrm{~g} / \mathrm{s}, 2 \mathrm{~K}$ Helium Cold Compressor System" Invited Talk at CEC 2001, vol 47

[8] R. Kersevan these proceedings

[9] D.Stout these proceedings 